\title{
Corrosion of Nanocrystalline Ni-W Coated Copper
}

\author{
Christos N. Panagopoulos*, Georgios D. Plainakis, Maria G. Tsoutsouva \\ Laboratory of Physical Metallurgy, National Technical University of Athens, Athens, Greece \\ Email: ${ }^{*}$ chpanag@metal.ntua.gr
}

Received 11 January 2015; accepted 31 January 2015; published 3 February 2015

Copyright (C) 2015 by authors and Scientific Research Publishing Inc.

This work is licensed under the Creative Commons Attribution International License (CC BY). http://creativecommons.org/licenses/by/4.0/

c) (i) Open Access

\begin{abstract}
The present study is dealing with the corrosion of copper coated with nanocrystalline nickeltungsten coating. Different plating bath compositions and conditions were used in order to produce nickel-tungsten coatings of different tungsten content $30 \%, 40 \%$ and $50 \%$ wt, with a thickness of $20 \mu \mathrm{m}$. The corrosion resistance of nickel-tungsten alloy coated copper was examined by a potentiodynamic polarisation technique in $\mathrm{NaCl}$ solution $(0.03 \mathrm{M}, 0.3 \mathrm{M}$ and $1 \mathrm{M})$ as a function of pH $(3,7,10)$ and temperature $\left(7^{\circ} \mathrm{C}, 30^{\circ} \mathrm{C}, 40^{\circ} \mathrm{C}\right)$ of the solution. It has been found that the $\mathrm{pH}$ value did not seem to affect the corrosion behaviour of the coated specimen remarkably, while the increase of solution temperature increased the corrosion rate of the coated copper specimen. It was finally confirmed that the corrosion products mainly consisted of tungsten and nickel oxides.
\end{abstract}

\section{Keywords}

\section{Nickel, Tungsten, Coating, Corrosion}

\section{Introduction}

Nickel-tungsten alloy coatings are widely used in a variety of industrial applications since they have the capability to enhance the technological properties of a metallic substrate. Tungsten with its unusual properties such as high melting point $\left(3410^{\circ} \mathrm{C}\right)$, low coefficient of linear thermal expansion $\left(4.3 \times 10^{-6} /{ }^{\circ} \mathrm{C}\right)$, high tensile strength $\left(410 \mathrm{Kg} / \mathrm{mm}^{2}\right)$ and one of the highest Young's modulus of elasticity $\left(3500 \mathrm{Kg} / \mathrm{mm}^{2}\right)$ can render excellent properties to its alloy.

Introduction of tungsten to nickel can lead to the formation of metallic coatings of improved durability, hardness [1], wear [2] and hot strength oxidation resistance and thus they could replace hard chromium coatings, as chromates are known to be highly toxic and carcinogenic [3]. On the other hand, the nickel-tungsten alloy coat-

\footnotetext{
${ }^{*}$ Corresponding author.
}

How to cite this paper: Panagopoulos, C.N., Plainakis, G.D. and Tsoutsouva, M.G. (2015) Corrosion of Nanocrystalline Ni-W Coated Copper. Journal of Surface Engineered Materials and Advanced Technology, 5, 65-72. 
ings exhibit good mechanical, magnetic and electrical properties [4]. Despite the fact that the corrosion behavior of nickel-tungsten coated metallic materials is of great importance, it has not yet been investigated extensively.

Specially the electrodeposited Ni-W coatings have some excellent properties such as mechanical strength, wear resistance and thermal stability. With the aid of electrodeposition technique, it is easy to control the grain size and several properties of Ni-W. These coatings have many useful applications in the industry such as electrical contacts and MEMS applications.

Sriraman et al. [5] investigated the anticorrosive behavior of the nickel-tungsten alloy coatings using polarization, electrochemical passivation and electrochemical impedance spectroscopy techniques. The coatings resistance to the corrosion was found to increase with the increase of tungsten content up to $7.54 \%$ at. and then to decrease.

Alimadadi et al. [6] studied the corrosion resistance of patterned nickel-tungsten alloys comprising 0\% - 26\% at. tungsten, with potentiodynamic polarization and electrochemical impedance spectroscopy in a medium containing chloride anions. They found that the corrosion resistance of single phase nickel-tungsten was superior to amorphous and dual phase nickel-tungsten coatings.

The aim of this work is to study the corrosive behavior of copper coated with electrodeposited nickel-tungsten coatings in $\mathrm{NaCl}$ solution of different concentration $(0.03 \mathrm{M}, 0.3 \mathrm{M}$ and $1.0 \mathrm{M}$ ), and different $\mathrm{pH}$ values (3, 7 and 10) and solution temperatures $\left(7^{\circ} \mathrm{C}, 30^{\circ} \mathrm{C}\right.$ and $\left.40^{\circ} \mathrm{C}\right)$, with the aid of the potentiodynamic polarization techniques. Additionally, the influence of the tungsten content (30 wt\%, $40 \mathrm{wt} \%, 50 \mathrm{wt} \%$ ) on the anticorrosive behavior of copper was also investigated.

\section{Experimental}

Nickel-tungsten alloy coatings were electrodeposited on copper substrates from a sodium citrate aqueous solution, using a two electrodes configuration. The used plating bath compositions and conditions in order to produce nickel-tungsten coatings with different tungsten content are given in Table 1 . As it is mentioned later, the tungsten content of grown electrodeposits was obtained with the use of E.D. Spectroscopy; 30\% wt, 40\% wt and $50 \%$ wt. The present plating bath composition is similar to that used in our previous work [7], with slight modifications in order to effectively control the \% wt tungsten content of the coatings.

A copper specimen having an exposed area of $1 \mathrm{~cm}^{2}$ was used as the cathode and a platinum sheet with the same exposed area was used as the anode. The distance between anode and cathode was 15 mm. Before electrodeposition, the copper substrates $\left(5 \times 2 \times 0.1 \mathrm{~cm}^{3}\right)$ were mechanically polished with SiC abrasive papers of increasing fineness (from 220 to 2000 grid), ultrasonically cleaned with distilled water and then activated by immersion in a 10\% w/v hydrochloric acid solution for $10 \mathrm{sec}$ and finally rinsed with distilled water.

The structure of the as-deposited nickel-tungsten alloy coatings were investigated with the aid of X-ray diffraction technique (XRD) (Bruker D8 Focus) using the Cu-K $\alpha 1$ line $(\mathrm{K}=1.5406 \AA$ ) in Bragg-Brentano geometry. The surface morphology and the tungsten composition of the produced coatings were analysed with the aid of a JEOL JSM 6380-LV Scanning Electron Microscope (SEM) equipped with an Energy Dispersive Spectrometer (EDS) and a Pro Image Analysis System. The coatings roughness was measured with Atomic Force Microscope (AFM, DME Dualscope DS95) and their thickness was estimated on the cross section of the specimens, using an Optical Microscope equipped with an Image Analysis program.

Potentiodynamic polarization curves were recorded for the coated copper specimens with nickel-tungsten coatings (coating thickness $=25 \mu \mathrm{m}$ ) containing different tungsten percentage $(30 \%, 40 \%$ and $50 \% \mathrm{wt}$ ), in three different aqueous solutions $\left(0.03 \mathrm{M} \mathrm{NaCl} / \mathrm{pH}=6 / \mathrm{T}=30^{\circ} \mathrm{C}, 0.3 \mathrm{M} \mathrm{NaCl} / \mathrm{pH}=6 / \mathrm{T}=30^{\circ} \mathrm{C}\right.$ and $1 \mathrm{M} \mathrm{NaCl} / \mathrm{pH}=$ $6 / \mathrm{T}=30^{\circ} \mathrm{C}$ ). In order to investigate the influence of the corrosive medium on the anticorrosive behavior of the produced nickel-tungsten alloy coated copper $\left(\mathrm{W}_{\text {content }}=40 \mathrm{wt} \%\right.$, Coating thickness $\left.=15 \mu \mathrm{m}\right)$, potentiodynamic corrosion experiments were also conducted in a $0.3 \mathrm{M} \mathrm{NaCl}$ solution with different $\mathrm{pH}(3,7,10)$ and temperature $\left(7^{\circ} \mathrm{C}, 30^{\circ} \mathrm{C}, 40^{\circ} \mathrm{C}\right)$.

The potentiodynamic corrosion experiments were realized with the aid of an EG \& G Potentiostat-Galvanostat instrument, while the reference electrode was a Saturated Calomel Electrode (SCE) and the auxiliary electrode was Graphite. The connection wire, between the Potentiostat and the working electrode, was made by such way in order to measure the cathodic or anodic potential, in fact the corrosion, of copper substrate. The scan rate of the applied potential was equal to $0.8 \mathrm{mV} / \mathrm{sec}$. From each specimen a $1 \mathrm{~cm}^{2}$ surface was selected for the potentiodynamic corrosion experiments. The remaining surface of the specimens was isolated with a special epoxy, 
Table 1. The plating bath compositions and conditions.

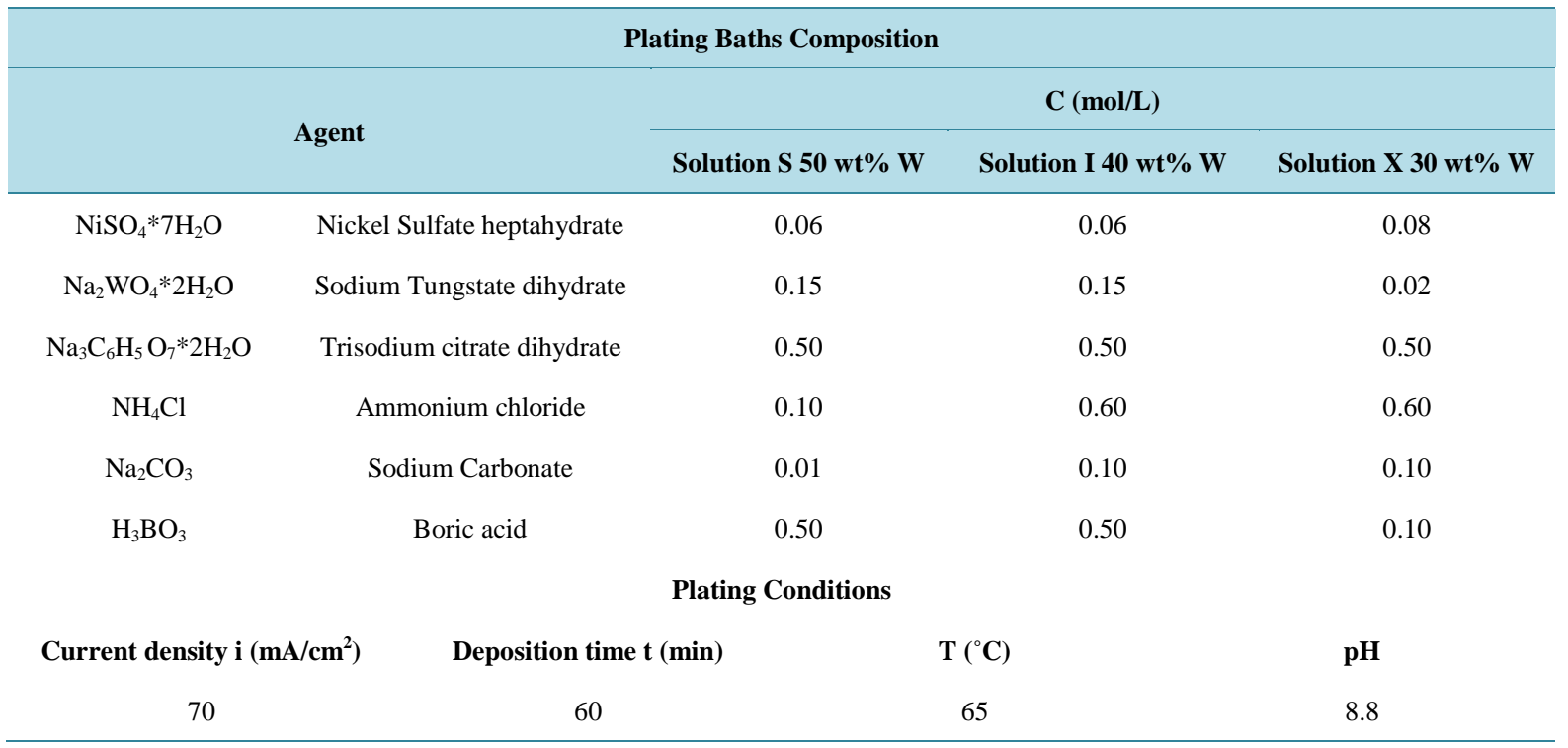

in order to avoid direct contact with the corrosive solution, apart from a small area, which was connected with the Potentiostat. Before starting the measurement, each specimen was left to attain a steady state, which was indicated by constant potential.

The corroded specimens were also studied with the aid of a Confocal Raman Microscope (Renishaw RM 1000).

It should be noted that each experiment was performed four times and the mean values are given in the graphs presented here.

\section{Results and Discussion}

Figure 1 shows the X-ray diffraction patterns obtained from three nickel-tungsten coatings with 30\% wt, 40\% wt and 50\% wt tungsten content. As mentioned earlier, the tungsten content in the electrodeposited coatings was obtained with the aid of E.D. Spectroscopy technique. The patterns given in Figure 1 correspond to solid solution of tungsten in nickel. Taking into account the phase diagram of nickel-tungsten system [8], it can be proposed that the following phases co-exist in the coatings.

$\mathrm{Ni}-30 \%$ wt W: solid solution of tungsten in nickel

$\mathrm{Ni}-40 \%$ wt W: solid solution of tungsten in nickel and intermetallic phase $\mathrm{Ni}_{4} \mathrm{~W}$

$\mathrm{Ni}-50 \%$ wt W: solid solution of tungsten in nickel and intermetallic phase NiW

The X-ray diffraction patterns of Figure 1, are shifted to lower value of diffraction angle in comparison with the theoretical value of $(1,1,1)$ nickel, $2 \theta=44.5$ degrees. This observation might be due to the compressive stress grown in the coatings [9] [10].

With the aid of the Debye-Scherrer equation, the grain size of the coatings in Figure 1 was calculated.

$$
D=\frac{0.94 \lambda}{B \cos \theta}
$$

where $\lambda$ is the $\mathrm{X}$-ray wavelength $(0.15405 \mathrm{~nm}), \theta$ is the diffraction angle and $B$ the approximate value of peak $\mathrm{Ni}(111)$ width.

The obtained values for the grain size of the coatings are the following:

Ni-30\% wt W: $D \approx 50 \mathrm{~nm}$

$\mathrm{Ni}-40 \%$ wt $\mathrm{W}: \quad D \approx 30 \mathrm{~nm}$

Ni-50\% wt W: $D \approx 10 \mathrm{~nm}$

From the above values, it can be said that the obtained nickel-tungsten coatings are nanocrystalline.

Under the selected experimental conditions the thickness of the above electrodeposited nanocrystalline nickel- 


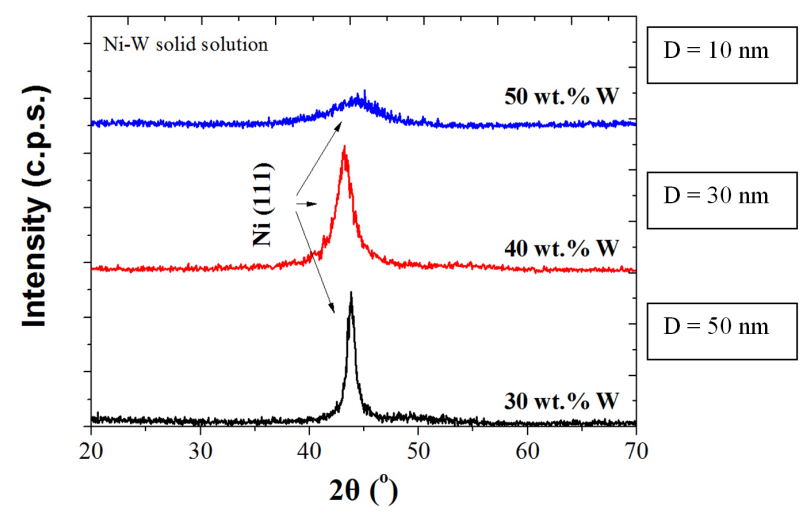

Figure 1. XRD patters of the nickel-tungsten alloy coated copper specimens in the range of $30 \%-50 \%$ wt $\mathrm{W}$.

tungsten alloy coatings on copper was found to be $25 \mu \mathrm{m}$, with the aid of a cross sectional micrograph.

Surface metallographic examination of the as deposited nanocrystalline nickel-tungsten alloy coatings on copper, containing different tungsten content are shown in Figure 2. Crack free Ni-W alloy coatings, with fairly uniform appearance containing globular crystallites were mainly obtained for tungsten content $30 \%$ wt. However, a further increase of tungsten content tends to cause microcracking of the deposit, probably due to the high internal stress in the coating [11]. From the same figure, it can be said that the tungsten content influences the surface morphology of the electrodeposited layers. As it can be seen, the increase of tungsten content leads to rougher coatings composed of larger globules that spontaneously form clusters.

The surface of the nanocrystalline nickel-tungsten alloy coatings was also studied with the aid of Atomic Force Microscopy. The topography of the representative nickel $40 \mathrm{wt} \%$ tungsten deposited coating is presented in Figure 3. As it has already seen in SEM micrographs, the surface of the electrodeposited coating is uniform and is composed of continuous globular regions of different sizes. As for the average roughness of the produced coating, it was found to be 70, 80 and $115 \mathrm{~nm}$ for the coatings containing $30 \mathrm{wt} \%, 40 \mathrm{wt} \%$ and $50 \mathrm{wt} \%$ tungsten respectively.

Figure 4 shows the potentiodynamic polarization curves of nickel-tungsten alloy coated copper in $\mathrm{NaCl}$ solutions with different $\mathrm{Cl}^{-}$concentration: a) 0.03 ; b) 0.3 and c) $1 \mathrm{M} \mathrm{NaCl}$ ), but at a constant value of $\mathrm{pH}$ and bath temperature $\left(\mathrm{pH}=6, \mathrm{~T}=30^{\circ} \mathrm{C}\right)$. From Figure 4 it is obvious that the tungsten content of the coating influences notably the anticorrosive behavior of the coated copper specimens.

From the experiment results, given in Figure 4 the follow observations could be obtained:

- In the three corrosive solutions, the corrosion potential of the Ni-50\% wt W coating shows the most negative corrosion potential. This might be duded to the higher cracking of the Ni-50\% wt W coating

- The anodic polarization curves of the Ni-50\% wt W and Ni-30\% wt W coated copper speciments show a continuous corrosion behaviour.

- A unique comment with respect to the effect of grain size of the corrosion of coatings on the corrosion behaviour of copper speciments cannot be given.

From Figure 5, it can be seen that the solution temperature $\left(\mathrm{T}=7^{\circ} \mathrm{C}, 30^{\circ} \mathrm{C}, 40^{\circ} \mathrm{C}\right)$ influences the anticorrosive behavior of the nanocrystalline nickel $40 \%$ wt tungsten alloy coated copper. It is clear that the increase of solution temperature increases the corrosion rate of the specimen as the anodic polarization curves have shifted to higher corrosion currents and lower corrosion potentials. This observation is probably due to the fact that the increase of solution temperature increases the mobility of the chloride ions within the solid phases in contact with the corrosive solution that are mainly responsible for the corrosion of copper.

The surface micrograph of two corroded specimens in $0.3 \mathrm{M} \mathrm{NaCl}$ solution, under the most corrosive conditions are present in Figure 6(a) $\mathrm{T}=7^{\circ} \mathrm{C}, \mathrm{pH}=3$, b) $\mathrm{T}=40^{\circ} \mathrm{C}, \mathrm{pH}=3$. It is obvious that the corrosion is more aggressive at the higher solution temperature. It can be also observed that the surface of the coating is more microcracked at the higher temperature.

An indicative Raman spectrum of a corroded nanocrystalline nickel $40 \mathrm{wt} \%$ tungsten coated copper is shown in Figure 7. The Raman spectrum exhibits a strong peak at $963 \mathrm{~cm}^{-1}$ that can be attributed to the symmetric $\mathrm{W}=$ $\mathrm{O}$ stretching mode of the dispersed tungsten oxide species on the surface of the nickel-tungsten alloy coating 


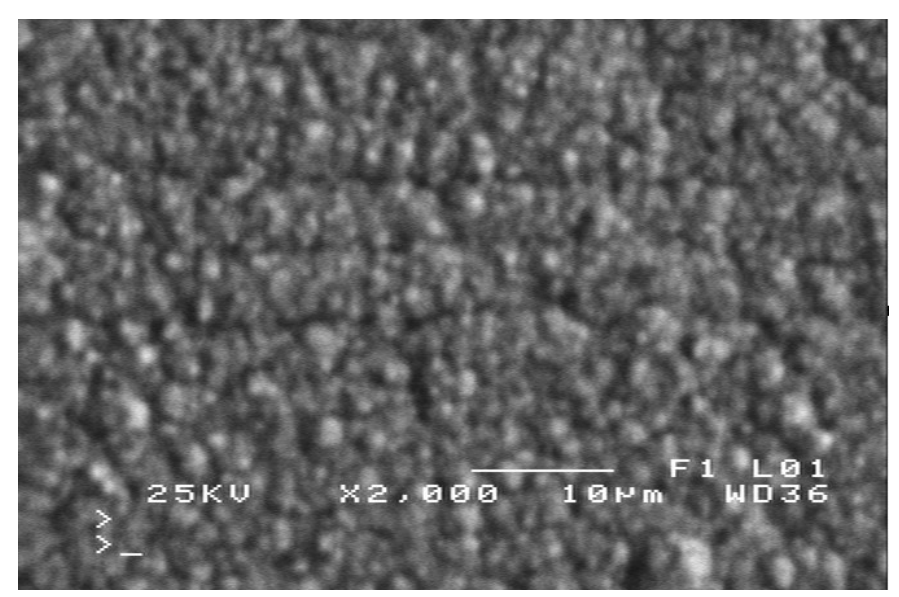

(a)

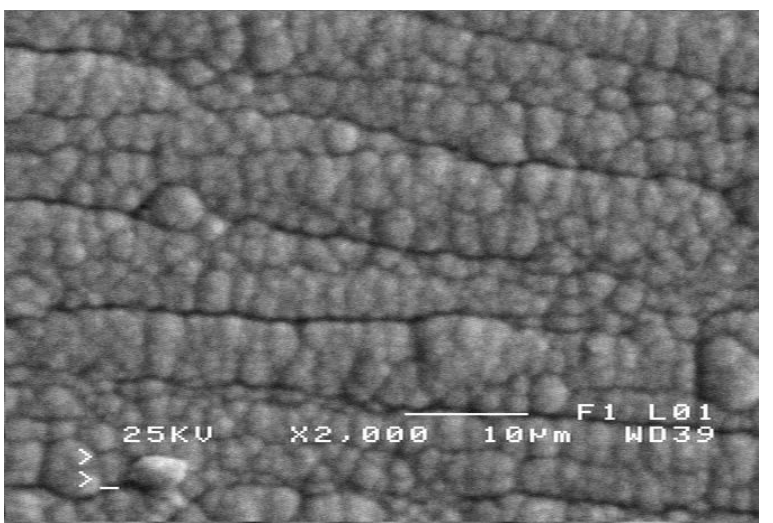

(b)

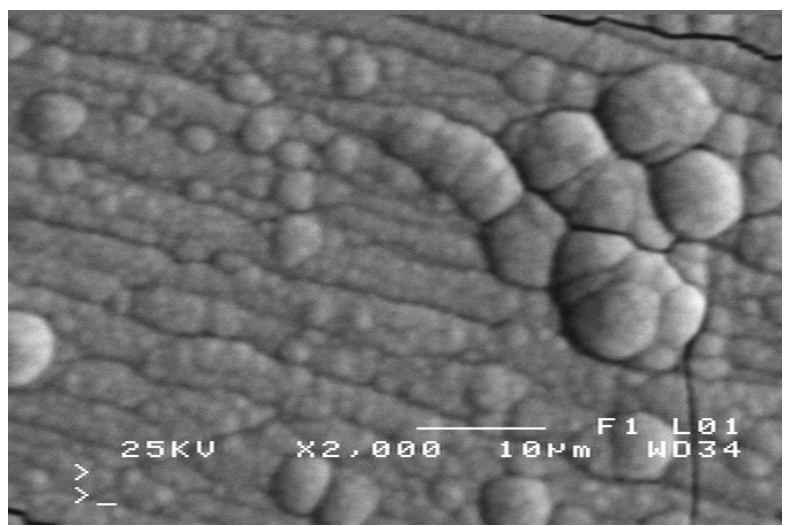

(c)

Figure 2. SEM micrograph of the produced nickel-tungsten alloy coatings containing different tungsten percentages: a) 30; b) 40 and c) $50 \mathrm{wt} \% \mathrm{~W}$.

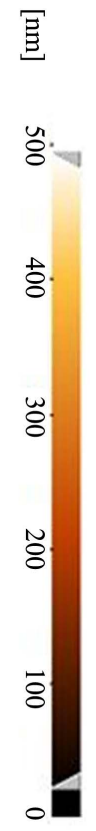

Figure 3. A representative AFM image of the electrodeposited nanocrystalline nickel — $40 \mathrm{wt} \%$ tungsten alloy coating surface. 


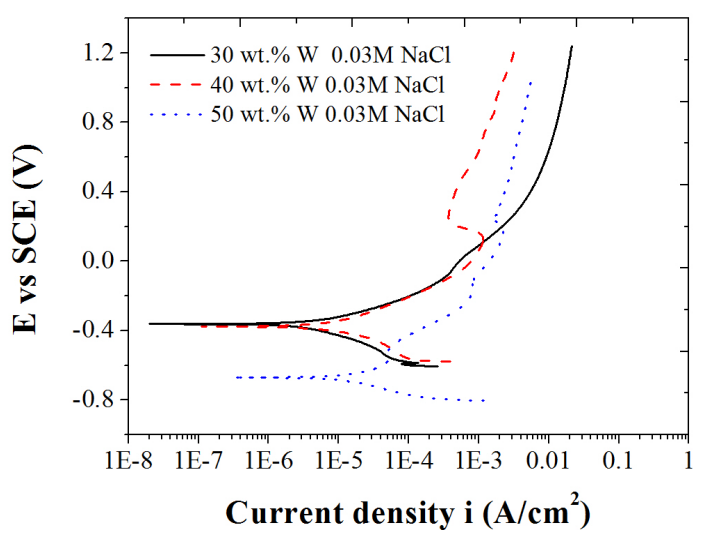

(a)

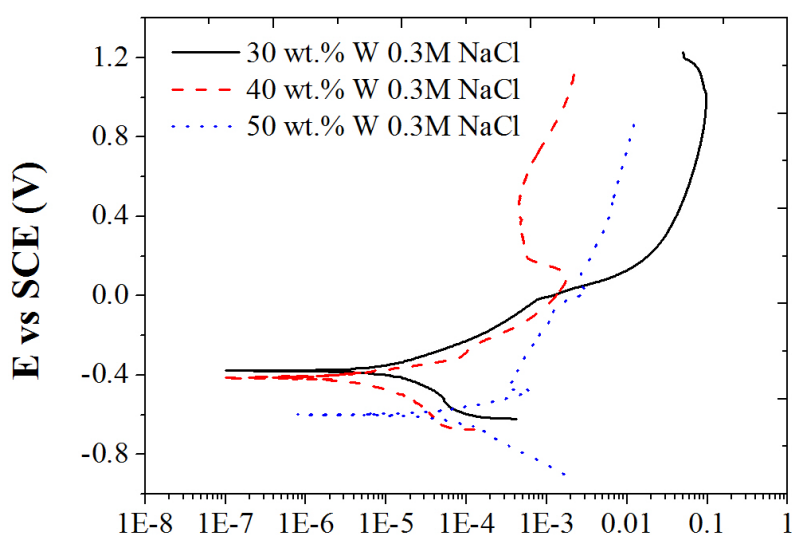

Current density i $\left(\mathrm{A} / \mathrm{cm}^{2}\right)$

(b)

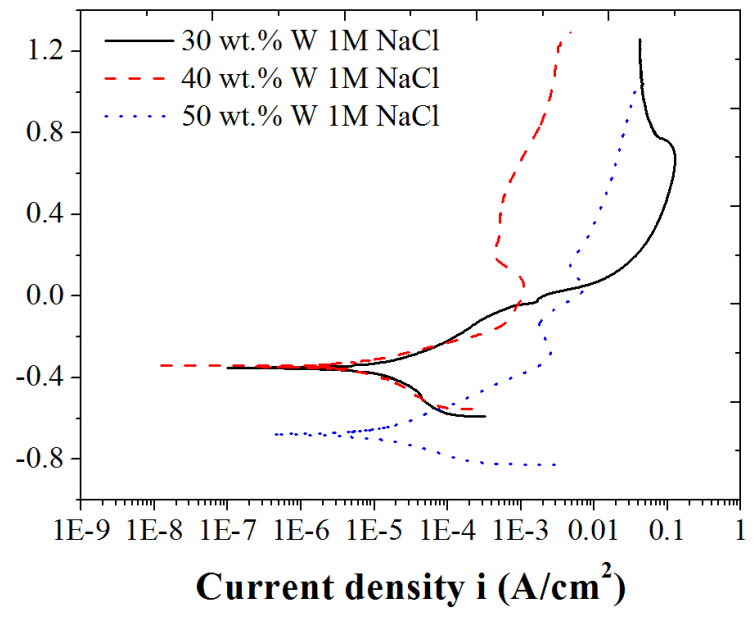

(c)

Figure 4. Potentiodynamic polarization curves of the nickel-tungsten alloy coated copper specimens with different wt\% W content, in $\mathrm{NaCl}$ solutions of different $\mathrm{Cl}^{-}$concentrations: a) 0.03 ; b) 0.3 and c) $1 \mathrm{M} \mathrm{NaCl}$, but a constant value of $\mathrm{pH}$ and bath temperature $\left(\mathrm{pH}=6, \mathrm{~T}=30^{\circ} \mathrm{C}\right)$.

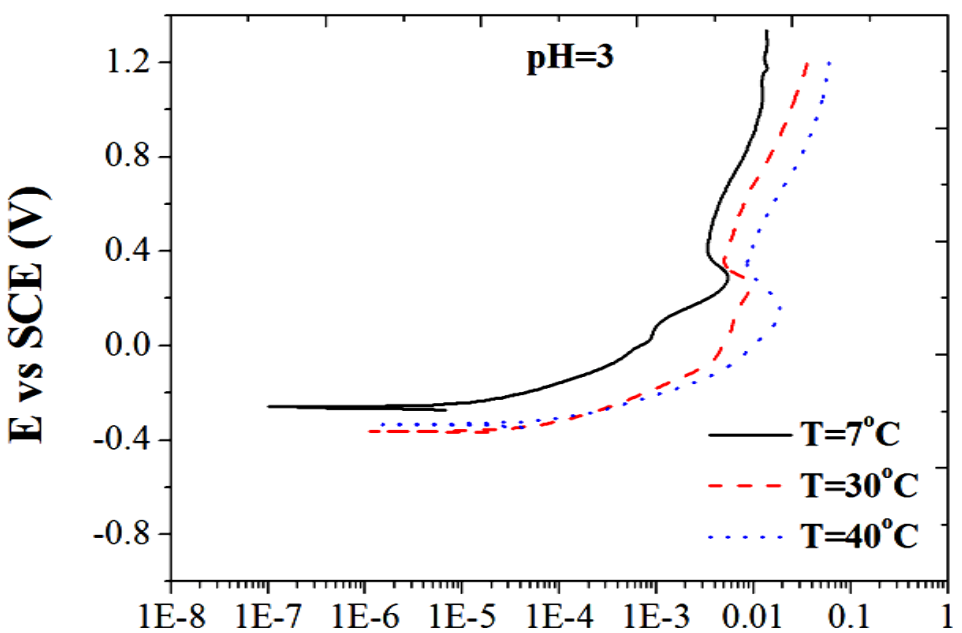

\section{Current density i (A/cm $\left.{ }^{2}\right)$}

Figure 5. Polarization curves of the nanocrystalline nickel-40 wt\% Tungsten alloy coated specimen in a $0.3 \mathrm{M} \mathrm{NaCl}$ solution as a function of solution temperature $\left(\mathrm{T}=7^{\circ} \mathrm{C}, 30^{\circ} \mathrm{C}, 40^{\circ} \mathrm{C}\right)$ but a constant $\mathrm{pH}$ value $(\mathrm{pH}=3)$. 


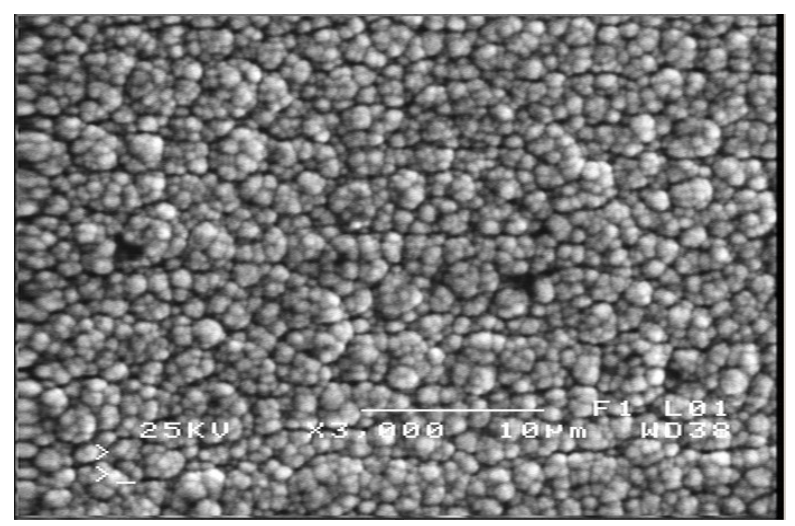

(a)

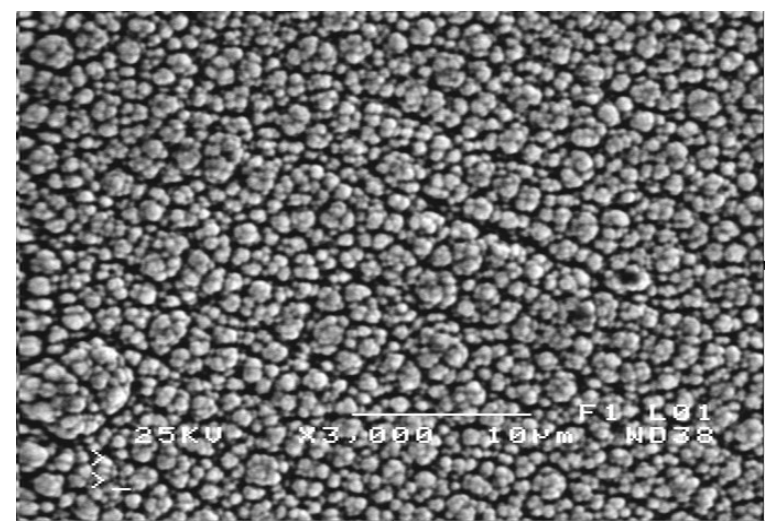

(b)

Figure 6. SEM micrographs of two corroded nanocrystalline nickel $-40 \mathrm{wt} \%$ tungsten alloy coated copper specimens in 0.3 $\mathrm{M} \mathrm{NaCl}$ solution, under different corrosive conditions: a) $\mathrm{T}=7^{\circ} \mathrm{C}, \mathrm{pH}=3$; b) $\mathrm{T}=40^{\circ} \mathrm{C}, \mathrm{pH}=3$.

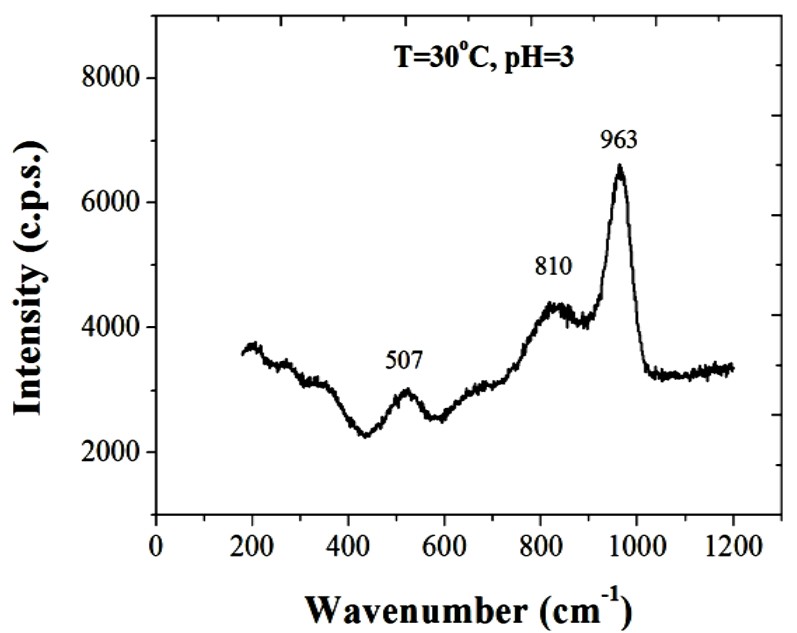

Figure 7. Raman spectrum of corroded nanocrystalline nickel-40 wt\% tungsten alloy coated copper in $0.3 \mathrm{M} \mathrm{NaCl}$ solution, with solution temperature $\mathrm{T}=30^{\circ} \mathrm{C}$ and $\mathrm{pH}$ value $\mathrm{pH}=3$.

[12]. Another peak at $810 \mathrm{~cm}^{-1}$ could be assigned to the $\mathrm{W}-\mathrm{O}$ stretching mode [13], which indicates the existence of crystalline $\mathrm{WO}_{3}$. The broad Raman band detected at $507 \mathrm{~cm}^{-1}$ can be correspond to the formation of $\mathrm{NiO}$ on the surface of the corroded specimen [14]. Thus, it was confirmed, with the aid of Raman spectroscopy, that the main corrosion products were $\mathrm{WO}_{3}$ and $\mathrm{NiO}$.

\section{Conclusions}

From the presented investigations, the following deductions could be made:

- Nanocrystalline Nickel-tungsten alloy coatings containing different wt\% W (30, 40 and 50) and thicknesses $15 \mu \mathrm{m}$ were electrodeposited on copper substrates, from alkaline sodium citrate aqueous solutions of different chemical compositions.

- XRD studies of the obtained coatings showed that the increase of the tungsten content, in the coating, resulted in a grain refinement. The coatings were observed to be nanocrystalline.

- The corrosion behavior of the nanocrystalline nickel-tungsten alloy coated copper speciments in NaCl solution showed that a clear relation between the corrosion rate and the $\mathrm{W}$ content was detected. The specimen containing $40 \mathrm{wt} \% \mathrm{~W}$ presented the best anticorrosive behavior, while a further increase of tungsten content caused a reduced corrosion resistance.

- For a constant solution pH value, the increase of solution temperature was found to increase the corrosion rate of the specimens. The corrosion mechanism was found to be mainly intergranular. 
With the aid of Raman spectroscopy, the corrosion products were found to mainly consist of $\mathrm{WO}_{3}$ and $\mathrm{NiO}$.

\section{References}

[1] Schuh, C.A., Nieh, T.G. and Iwasaki, H. (2003) The Effect of Solid Solution W Additions on the Mechanical Properties of Nanocrystalline Ni. Acta Materialia, 51, 431-443. http://dx.doi.org/10.1016/S1359-6454(02)00427-5

[2] Palaniappa, M. and Seshadri, S.K. (2008) Friction and Wear Behavior of Electroless Ni-P and Ni-W-P Alloy Coatings. Wear, 265, 735-740. http://dx.doi.org/10.1016/j.wear.2008.01.002

[3] Krishnan, R.M., Joseph Kennedy, C., Jayakrishnan, S., Sriveeraraghavan, S., Natarajan, S.R. and Venkatakrishnan, P.G. (1955) Electrodeposition of Nickel-Tungsten Alloys. Metal Finishing, 93, 33-39. http://dx.doi.org/10.1016/0026-0576(95)91308-A

[4] Haj-Taieb, M., Haseeb, A.S.M.A., Caulfield, J., Bade, K., Aktaa, J. and Hemker, K.J. (2008) Thermal Stability of Electrodeposited LIGA Ni-W Alloys for High Temperature MEMS Applications. Microsystem Technologies, 14, 15311536. http://dx.doi.org/10.1007/s00542-007-0536-5

[5] Sriraman, K.R., Raman, S.G.S. and Seshadri, S.K. (2007) Corrosion Behaviour of Electrodeposited Nanocrystalline Ni-W and Ni-Fe-W Alloys. Materials Science and Engineering: A, 460-461, 39-45. http://dx.doi.org/10.1016/j.msea.2007.02.055

[6] Alimadadi, H., Ahmadi, M., Aliofkhazraei, M. and Younesi, S.R. (2009) Corrosion Properties of Electrodeposited Nanocrystalline and Amorphous Patterned Ni-W Alloy. Materials \& Design, 30, 1356-1361. http://dx.doi.org/10.1016/j.matdes.2008.06.036

[7] Panagopoulos, C.N., Plainakis, G.D. and Lagaris, D.A. (2011) Nanocrystalline Ni-W Coatings on Copper. Materials Science and Engineering: B, 176, 477-479. http://dx.doi.org/10.1016/j.mseb.2010.03.058

[8] Hansen, M. (1958) Constitution of Binary Alloys. Mc Graw-Hill, New York, 1058.

[9] Panagopoulos, C.N. and Michaelidis, A. (1992) Laser Surface Treatment of Copper. Journal of Materials Science, 27, 1280-1284. http://dx.doi.org/10.1007/BF01142038

[10] Panagopoulos, C.N., Christou, G. and Danvelio, G. (1993) Laser Treatment of Zinc Coated Aluminium. Transactions of the Institute of Metal Finishing, 71, 65-67.

[11] Krolikowski, A., Płonska, E., Ostrowski, A., Donten, M. and Stojek, Z. (2009) Effects of Compositional and Structural Features on Corrosion Behavior of Nickel-Tungsten Alloys. Journal of Solid State Electrochemistry, 13, $263-275$. http://dx.doi.org/10.1007/s10008-008-0712-2

[12] Xu, B., Dong, L., Fan, Y. and Chen, Y. (2000) A Study on the Dispersion of $\mathrm{NiO}$ and/or $\mathrm{WO}_{3}$ on Anatase. Journal of Catalysis, 193, 88-95. http://dx.doi.org/10.1006/jcat.2000.2833

[13] Ramani, N.C., Sullivan, D.L., Ekerdt, J.G., Jehng, J.M. and Wachs, I.E. (1998) Selective Oxidation of 1-Butene over Silica-Supported Cr(VI), Mo(VI), and W(VI) Oxides. Journal of Catalysis, 176, 143-154. http://dx.doi.org/10.1006/jcat.1998.2056

[14] Ravi Shankar, A., Mathiya, S., Thyagarajan, K. and Kamachi Mudali, U. (2010) Corrosion and Microstructure Correlation in Molten LiCl-KCl Medium. Metallurgical and Materials Transactions A, 41, 1815-1825. http://dx.doi.org/10.1007/s11661-010-0223-5 
Scientific Research Publishing (SCIRP) is one of the largest Open Access journal publishers. It is currently publishing more than 200 open access, online, peer-reviewed journals covering a wide range of academic disciplines. SCIRP serves the worldwide academic communities and contributes to the progress and application of science with its publication.

Other selected journals from SCIRP are listed as below. Submit your manuscript to us via either submit@scirp.org or Online Submission Portal.
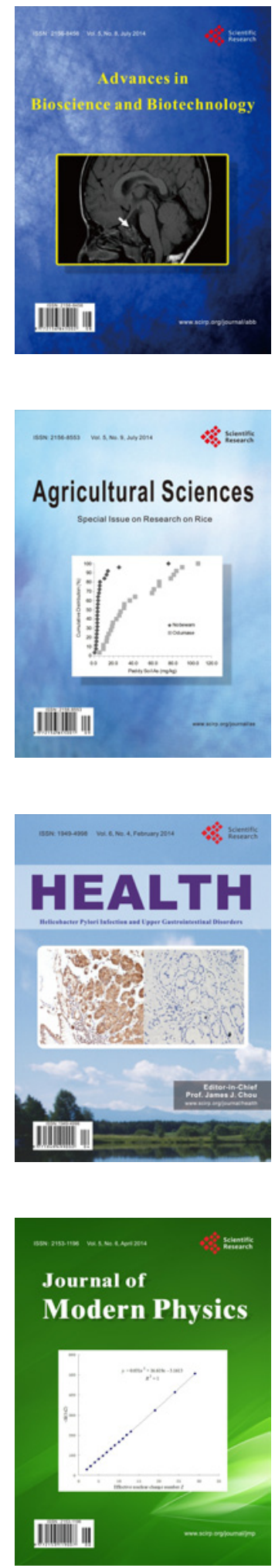
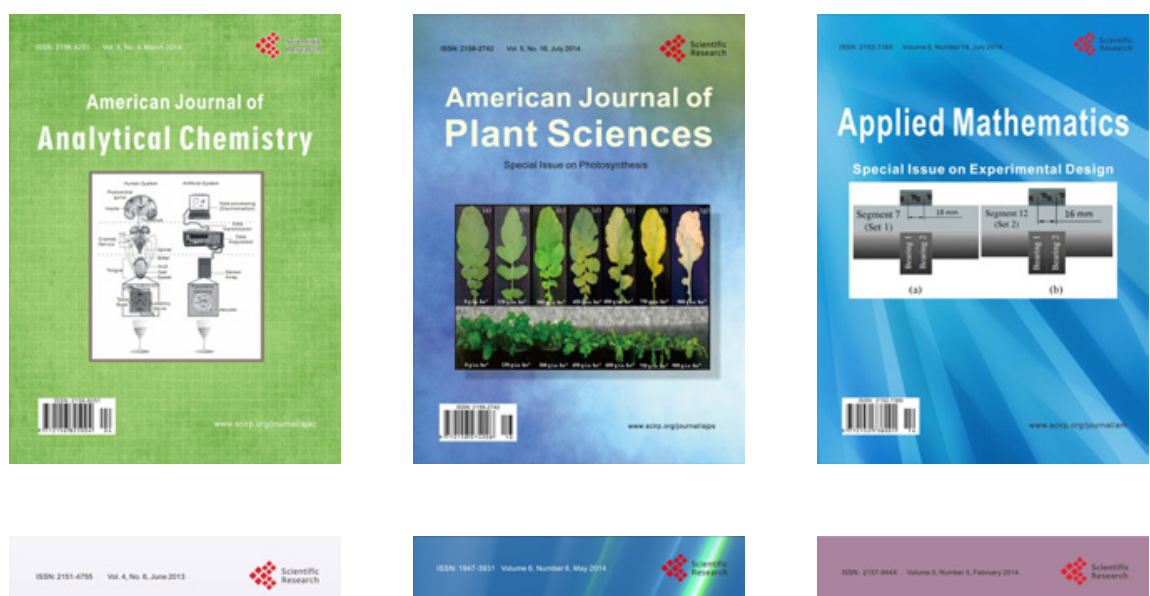

Creative Education
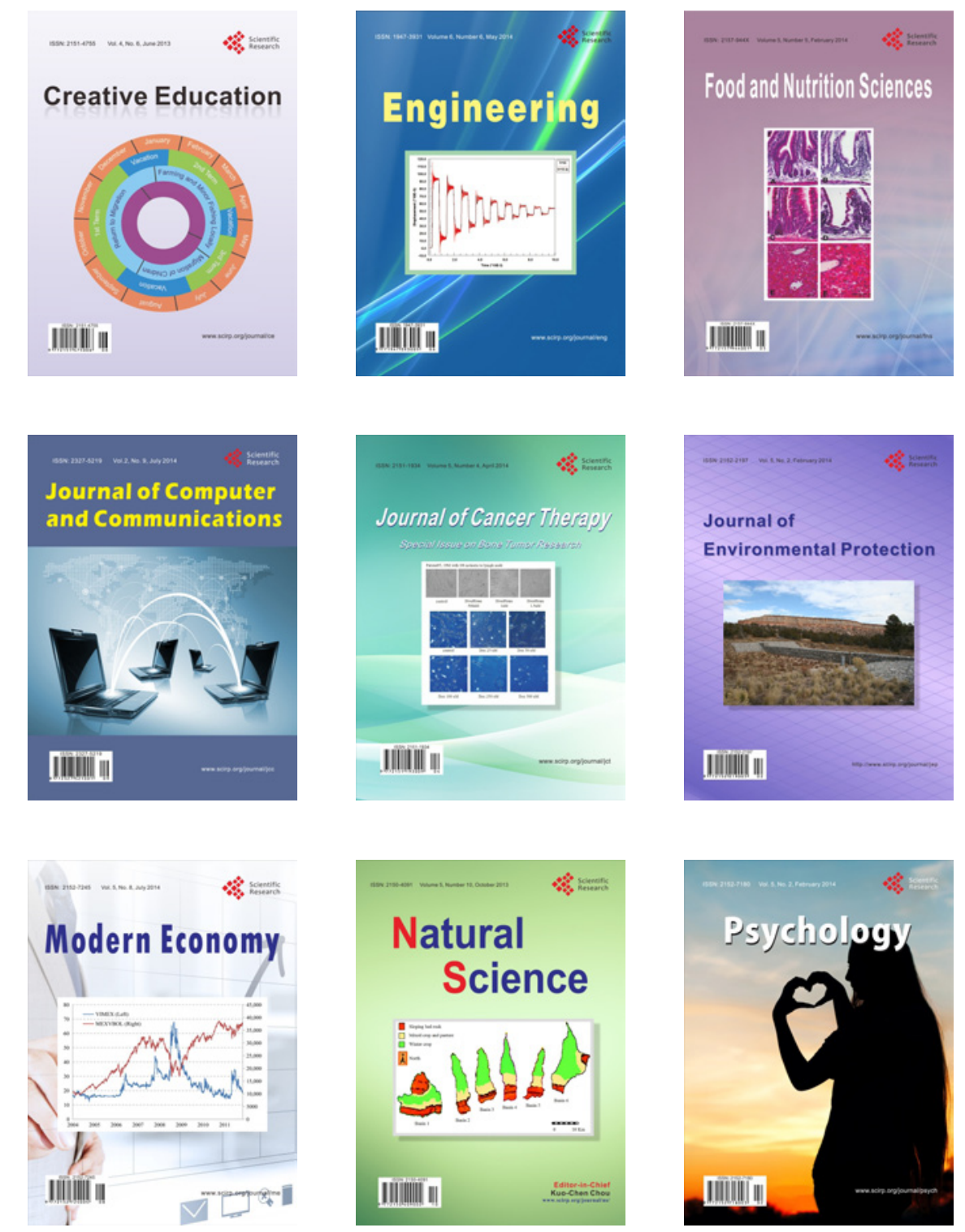